\title{
PERLAKUAN PENGOLAHAN BAHAN BAKU PADA INSTALASI BIOGAS DI KELURAHAN SEMATANG BORANG KOTA PALEMBANG PROVINSI SUMATERA SELATAN
}

\section{Raw Material Processing Treatment in Biogas Installation in Sematang Borang Village, Palembang, South Sumatera}

\author{
Irnanda Pratiwi*, Winny Andalia, Madagaskar, Faizah Suryani, Selvia Aprilyanti \\ Fakultas Teknik, Universitas Tridinanti Palembang
}

Article history

Received: Jun 10, 2021;

Accepted: Jul 12, 2021

* Corresponding author:

E-mail:

irnanda_pratiwi@univ-

tridinanti.ac.id

DOI: https://doi.org/10.465

49/igkojei.v2i2.229

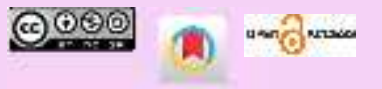

\begin{abstract}
RT 04 Sematang Borang Village has utilized a biogas installation to process cow manure into both solid and liquid organic fertilizer and also produce biogas. The biogas fermentation process and organic fertilizer processing experienced problems due to the grass within the cow manure entering the digester, which was caused by a leak in the digester cover and the low quality of organic fertilizer produced in the outlet tub. This community service activity aims to treat waste raw materials so that the fermentation process can take place optimally. The presence of animal feed or grass in the inlet tub will interfere with the fermentation process and cause the digester lid to leak. In the implementation of this community service program, the focus is on improving the digester and adding tools to aid the process of separating cow dung raw materials so that the fermentation process can be optimized. The biogas formation process requires an airtight, oxygen-free, or anaerobic (closed) space. Treatment is done by separating cow manure raw materials from feed grass by using a filter to produce good raw materials in the biogas fermentation process. So that cow manure that enters the digester can be fermented optimally.
\end{abstract}

Keywords: Biogas; Digester; Fermentation; Cow Manure

\section{ABSTRAK}

RT 04 Kelurahan Sematang Borang, sudah menggunakan instalasi biogas yang gunanya untuk mengolah kotoran ternak sapi menjadi pupuk organik padat dan cair serta juga menghasilkan biogas. Proses fermentasi biogas dan pengolahan pupuk organik ini mengalami kendala yang disebabkan rumput kotoran sapi yang masuk ke dalam digester yang disebabkan oleh bocornya tutup digester serta belum maksimalnya kualitas pupuk organik yang dihasilkan pada bak outlet rendah. Kegiatan pengabdian kepada masyarakat ini bertujuan untuk melakukan treatment pada bahan baku limbah sehingga proses fermentasi dapat berlangsung optimal. Adanya pakan ternak atau rumput di dalam bak inlet akan mengganggu proses fermentasi dan menyebabkan tutup digester bocor. Pada kegiatan pelaksanaan program pengabdian kepada masyarakat ini difokuskan pada perbaikan digester dan penambahan alat untuk proses pemisahan bahan baku kotoran sapi agar proses fermentasi lebih maksimal. Proses pembentukan biogas membutuhkan ruang yang kedap udara, tanpa oksigen atau anaerob (tertutup). Perlakuan pengolahan (treatment) dengan pemisahan bahan baku kotoran sapi dengan rumput pakan dengan menggunakan alat penyaring untuk menghasilkan bahan baku yang baik pada proses fermentasi biogas. Sehingga kotoran sapi yang masuk ke dalam digester dapat difermentasi secara maksimal

Kata kunci: Biogas; Digester; Fermentasi; Kotoran Sapi 


\section{PENDAHULUAN}

Dari dulu hingga sekarang, sektor pertanian memiliki peranan yang sangat penting dalam perekonomian nasional, demikian juga dalam pembangunan ekonomi di daerah Kecamatan Sematang Borang Kota Palembang Provinsi Sumatera Selatan. Produk - produk pertanian atau tanaman hortikultura yang dihasilkan dari daerah tersebut antara lain sayur - mayur, rempah - rempah dan buah - buahan. Selain produk pertanian, sebagian masyarakat juga menjalankan kegiatan bidang peternakan yaitu sapi, kambing, bebek dan ayam. Kelurahan Suka Mulya adalah salah satu dari empat kelurahan yang ada di Kecamatan Sematang Borang. Pada tahun 1952, Kelurahan Suka Mulya masih bernama Penggowo Marga Gasing, kemudian pada tahun 1965 sampai tahun 1982 menjadi Desa Suka Mulya. Pada tahun 2000 sampai dengan sekarang Desa Suka Mulya menjadi Kelurahan Suka Mulya.

Kelurahan Suka Mulya mempunyai luas wilayah $\pm 1.160,85$ Ha. Keadaan geografis yang terdiri dari dataran rendah. Jarak dari pusat kecamatan $\pm 2 \mathrm{Km}$ dan jarak dari pusat kota $\pm 12 \mathrm{Km}$. Keadaan tanahnya sebagian besar terdiri dari tanah rawa - rawa. Hampir seluruh wilayah memiliki potensi pengembangan usaha pertanian seperti pasang surut, tegalan/lahan pasang surut yang dikeringkan, perkebunan rakyat dan merupakan dataran rendah dengan ketinggian 2,5 meter dari permukaan laut. Kelurahan Suka Mulya merupakan daerah rawa - rawa dengan tingkat tropis basah dengan curah hujan pertahun antara $1540 \mathrm{~mm}, 110$ hari/hujan/tahun.

Pada sektor peternakan, limbah ternak merupakan salah satu masalah yang dihadapi oleh pengelola ternak, seperti peternak sapi, kambing, ayam dan bebek. Limbah merupakan bahan organik atau anorganik yang tidak termanfaatkan lagi, sehingga dapat menimbulkan masalah serius bagi lingkungan jika tidak ditangani dengan baik. Limbah dapat berasal dari berbagai sumber hasil buangan dari suatu proses produksi salah satunya limbah peternakan (Pratiwi dkk, 2019). Khususnya untuk peternak sapi, limbah yang dihasilkan setiap harinya, jika tidak diolah, akan terakumulasi banyak dan akan mengganggu lingkungan. RT 04 Kelurahan Sematang Borang, sudah menggunakan instalasi biogas yang gunanya untuk mengolah kotoran ternak sapi menjadi pupuk organik padat dan cair serta juga menghasilkan biogas.

Biogas atau sering pula disebut gas bio merupakan gas yang timbul jika bahan-bahan seperti kotoran hewan, kotoran manusia, ataupun sampah, direndam di dalam air dan disimpan di tempat tertutup atau anaerob (tanpa oksigen dari udara). Proses kimia terbentuknya gas cukup rumit, tetapi cara menghasilkannya tidak sesulit proses pembentukannya. Hanya dengan teknologi sederhana gas ini dapat dihasilkan dengan baik (Sulistiyanto dkk, 2016). Biogas dapat dibuat dari kotoran ternak, limbah industri tahu, atau sampah organik rumah tangga atau pasar. Biogas memiliki prospek yang baik sebagai alternatif energi terbarukan yang dapat dikembangkan di Indonesia yang sedang mengalami krisis energi yang ditandai dengan semakin langka dan tingginya harga bahan bakar yang berdampak pada semakin tingginya biaya produksi pembangkit tenaga listrik (Widyastuti dkk, 2013). 
Dikarenakan keterbatasan lahan ternak, maka peternak mengalami kesulitan dalam mengolah bahan baku limbah ternak yaitu kotoran sapi yang bercampur dengan rumput pakan ternak. Proses fermentasi biogas dan pengolahan pupuk organik ini mengalami kendala yang disebabkan rumput kotoran sapi yang masuk ke dalam digester yang menyebabkan tutup digester bocor dan kualitas pupuk organik pada bak outlet rendah. Kegiatan pengabdian kepada masyarakat ini bertujuan untuk melakukan treatment pada bahan baku limbah sehingga proses fermentasi dapat berlangsung optimal.

\section{METODE}

Kegiatan pengabdian masyarakat ini dilaksanakan pada tanggal 15 Februari - 15 Maret 2021 yang berlokasi di Kelurahan Sukamulya, Kecamatan Sematang Borang, Palembang, Provinsi Sumatera Selatan. Kegiatan ini melibatkan peran serta mahasiswa Universitas Tridinanti Palembang dan warga RT 04 Kelurahan Sukamulya. Kegiatan difokuskan pada perbaikan digester dan penambahan alat untuk proses pemisahan bahan baku kotoran sapi agar proses fermentasi lebih maksimal.

Proses perbaikan instalasi biogas diawali dengan melakukan analisis masalah dimana ditemukan bahwa bahan baku kotoran sapi masih bercampur dengan pakan ternak atau rumput. Adanya pakan ternak atau rumput di dalam bak inlet akan mengganggu proses fermentasi dan menyebabkan tutup digester bocor (Gambar 1), karena proses fermentasi hanya membutuhkan bahan baku kotoran sapi tanpa ada bahan lainnya. Selanjutnya mahasiswa bersama masyarakat merancang alat yang dapat memisahkan antara kotoran sapi dengan rumput sisa pakan ternak dalam bak inlet. Rancangan alat ditunjukkan pada (Gambar 2).
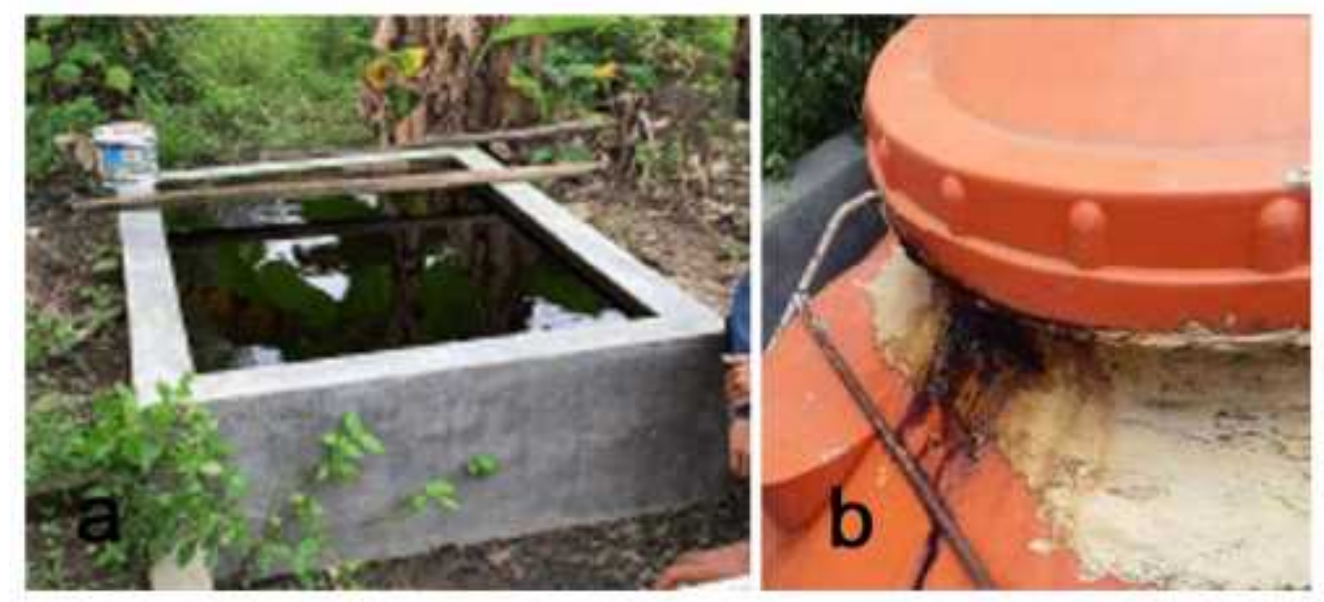

Gambar 1. (a). Hasil dari pupuk organik yang belum optimal, (b). Kebocoran pada digester 

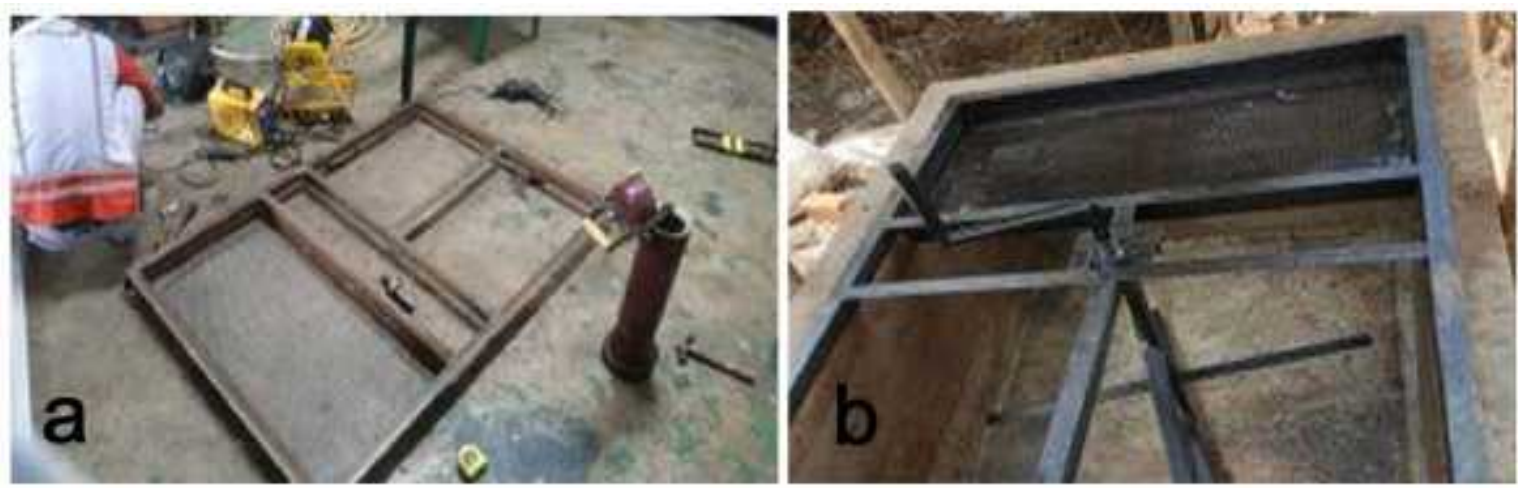

Gambar 2. (a). Bagian atas alat pemisah kotoran sapi dengan rumput, (b). Alat pemisah terpasang pada bak inlet

Bahan dan alat yang dibutuhkan dalam pembuatan alat pemisah antara kotoran sapi dan rumput sisa pakan adalah sebagai berikut: Pipa PVC 3/4 inch; Elbow 3/4 inch; Seal Tape 1 inch; Lem Epoxy non SAG; Dop 4 inch; Soc 3/4 inch; Soc $1 \frac{1}{2}$ inch; Selang 10 meter; Lem pipa pvc; Lem epoxy dexton; Bearing 4 inch Besi siku 2 batang; Kawat stainless; Pipa besi; Cat platone; Kuas; Stop kran 1/2 inch; Thinner; Gergaji besi; Tali; Paku; Meteran.

Langkah pertama yang dilakukan adalah pengosongan dan pembersihan bak inlet, bak outlet dan digester agar bahan baku lain yang mengganggu proses fermentasi dapat dibuang (Gambar 3).
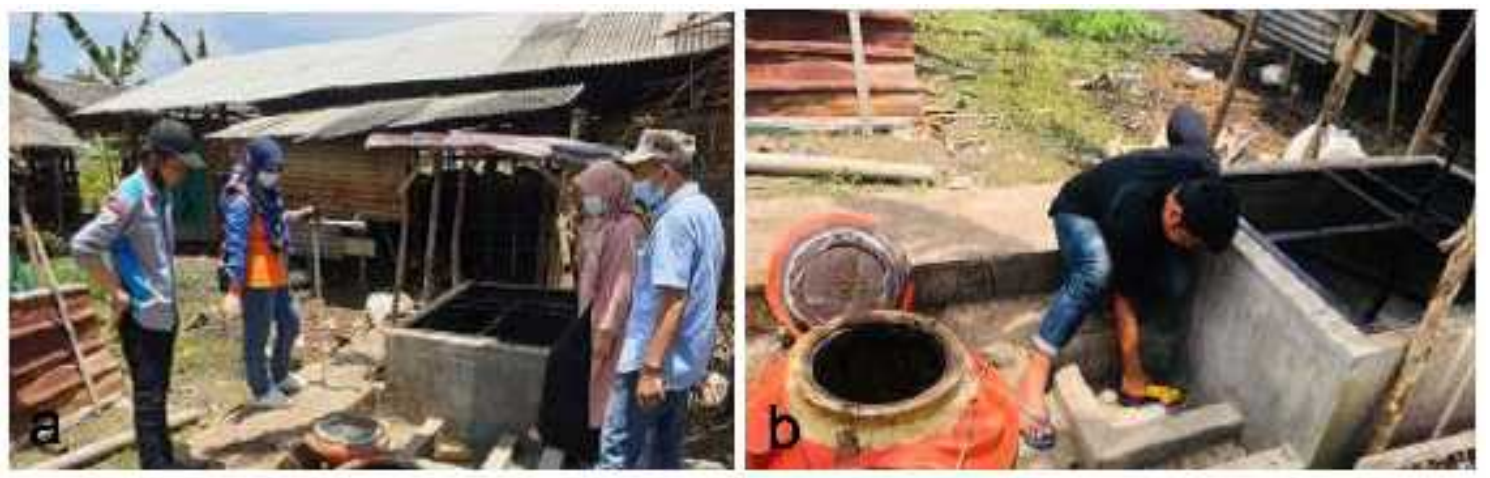

Gambar 3. (a). Pembersihan bak inlet dan outlet, (b). Pembersihan digester biogas

Langkah selanjutnya dengan pemasangan alat pemisah antara kotoran sapi dan rumput dan dilanjutkan dengan memasukkan bahan baku pada instalasi biogas. Pada langkah ini, sebelum masuk ke bak inlet, kotoran sapi melewati proses penyaringan agar rumput yang ada pada kotoran sapi tidak ikut masuk ke dalam bak inlet yang menyebabkan kendala pada proses fermentasi biogas (Gambar 4). 

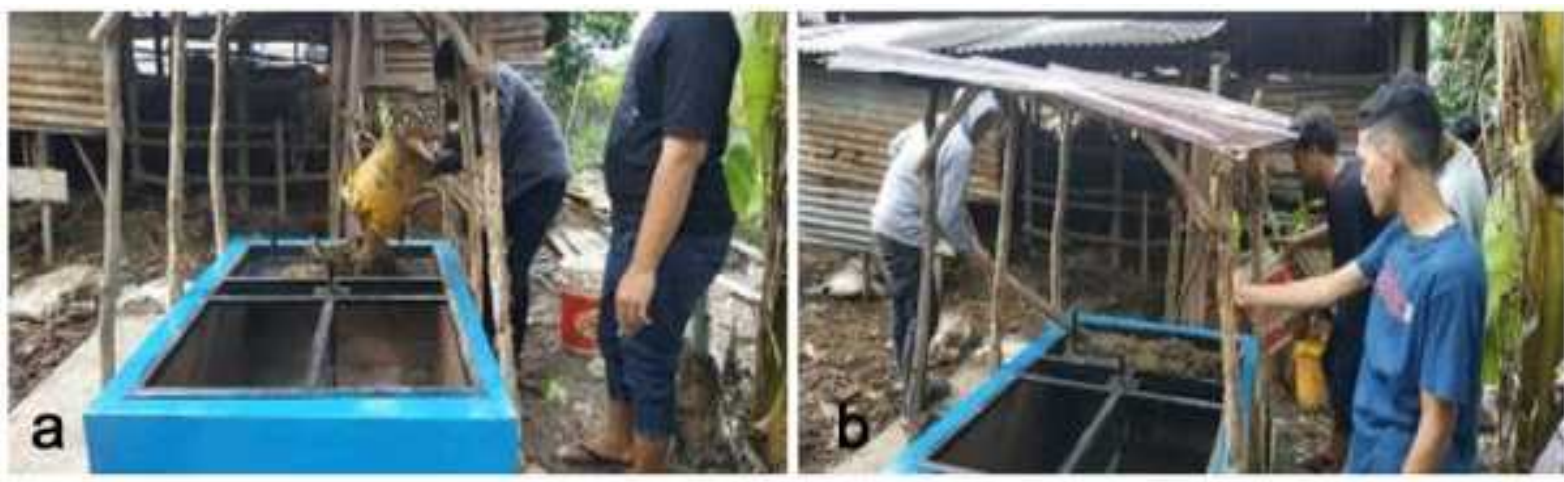

Gambar 4. (a). Kotoran sapi dimasukkan bak inlet, (b). Penyaringan kotoran sapi

Tahap akhir dalam proses pengolahan kotoran sapi menjadi biogas dan pupuk organik ini adalah fermentasi kotoran sapi di dalam digester biogas selama kurang lebih 3 - 4 hari, dimana kotoran sapi yang digunakan dalam proses fermentasi adalah kotoran sapi yang masih baru (berumur kurang lebih 2 - 3 hari). Pada proses fermentasi ini, biogas yang dihasilkan akan membuat pupuk cair dan padat masuk ke bak outlet (Gambar 5a).

\section{HASIL DAN PEMBAHASAN}

Pada kegiatan ini, dihasilkan alat pemisah antara kotoran sapi dengan rumput sisa pakan ternak berbahan besi yang dilengkapi dengan kawat penyaring dan besi pengaduk (Gambar 5b). Kawat penyaring digunakan untuk menyaring rumput agar tidak masuk ke dalam bak inlet. Besi pengaduk digunakan untuk mengaduk atau mencampur antara kotoran sapi dan air hingga membentuk lumpur (slurry) kotoran sapi. Langkah awal dalam perlakuan bahan baku yaitu menyaring kotoran sapi dan rumput, lalu kotoran sapi akan jatuh ke dalam bak inlet sedangkan rumput akan tertinggal di penyaring kawat. Selanjutnya kotoran sapi yang sudah disaring, dicampurkan dengan air menggunakan besi pengaduk hingga membentuk slurry, kemudian dialirkan ke dalam digester. Proses pemilahan bahan banyak dilakukan untuk memisahkan material sesuai ukuran atau kategori yang dikehendaki (Mujianto \& Rahmi, 2019).

Digester yang digunakan pada proses fermentasi telah diperbaiki pada bagian atas yang mengalami kebocoran. Perbaikan dilakukan dengan membongkar dan membersihkan tutup digester dari sisa perekat lama dan melakukan perbaikan dengan menggunakan perekat (seal) yang baru (Gambar 5c). Hal ini agar proses fermentasi yang bersifat anaerob dapat berlangsung optimal. Proses pembentukan biogas membutuhkan ruang yang kedap udara, tanpa oksigen atau anaerob (tertutup) (Pratiwi dkk, 2019). Kondisi ini menjadi kelebihan dari sistem biogas, yaitu tidak adanya bau atau aroma dari proses pengolahan biogas. Mekanisme pembentukan biogas secara umum, yaitu (Wahyuni, 2017) :

$$
\text { Bahan Organik } \stackrel{\text { Mukroorganisme anaerob }}{\longrightarrow} \mathrm{CH}_{4}+\mathrm{CO}_{2}+\mathrm{H}_{2}+\mathrm{NH}_{3}
$$


Digester atau reaktor biogas merupakan alat utama dalam produksi biogas. Proses fermentasi yang terjadi di dalam digester akan berlangsung beberapa hari setelah bahan baku kotoran sapi yang telah dicampur dengan air, dimasukkan ke dalam bak inlet, lalu dilanjutkan ke dalam digester. Salah satu digester yang dapat digunakan dalam instalasi biogas adalah digester Fixed Drum berbahan fiber HDPE (High Density Polyethylene) (Pratiwi dkk, 2019).
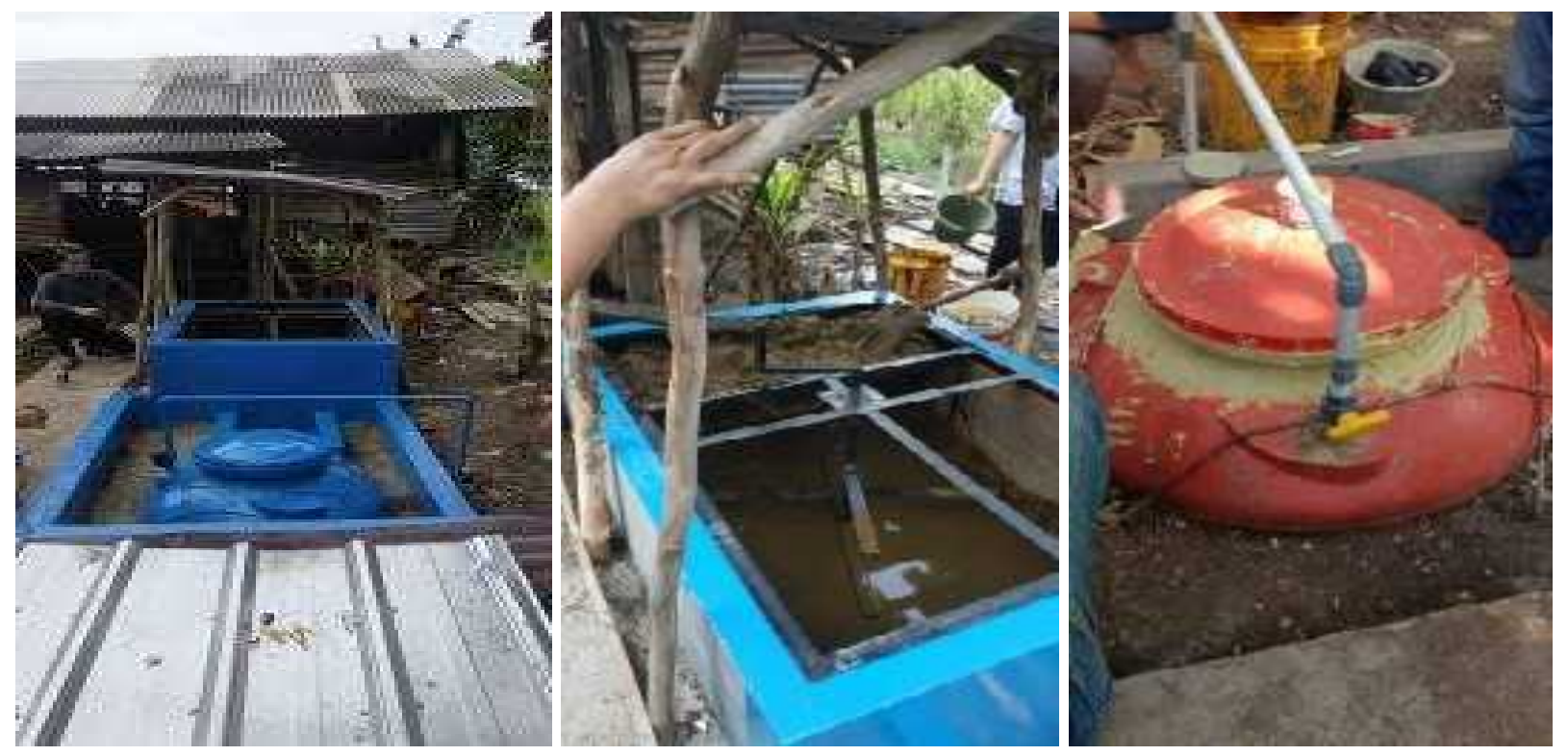

Gambar 5. (a). Bak outlet instalasi biogas, (b). Alat pemisah berbahan besi, (c) Bagian atas digester yang telah diperbaiki

Kotoran sapi yang baru memiliki kandungan bakteri metan yang masih banyak. Bakteri methan tersebut yang akan membantu proses fermentasi kotoran sapi menjadi pupuk cair dan padat organik serta biogas. Fermentasi biogas berbahan kotoran sapi akan berlangsung optimal dalam kondisi cuaca cerah-panas. Keadaan tersebut mempercepat proses fermentasi yang dilakukan oleh bakteri metana di dalam digester. Gas methane akan dihasilkan pada hari ke-5, namun gas tersebut masih mengandung udara yang tercampur pada saat proses fermentasi pertama kali terjadi di dalam digester. Gas yang dihasilkan dapat maksimum tercapai di hari ke-20 (Sulistiyanto et al., 2016). Gas yang dihasilkan dari fermentasi ditampung di plastik penampung yang terbuat dari bahan PVC (Gambar 6a), sedangkan hasil fermentasi berupa bahan padat dan cair, yang dengan tekanan dari biogas akan mengalir ke dalam bak outlet (Gambar 6b). 

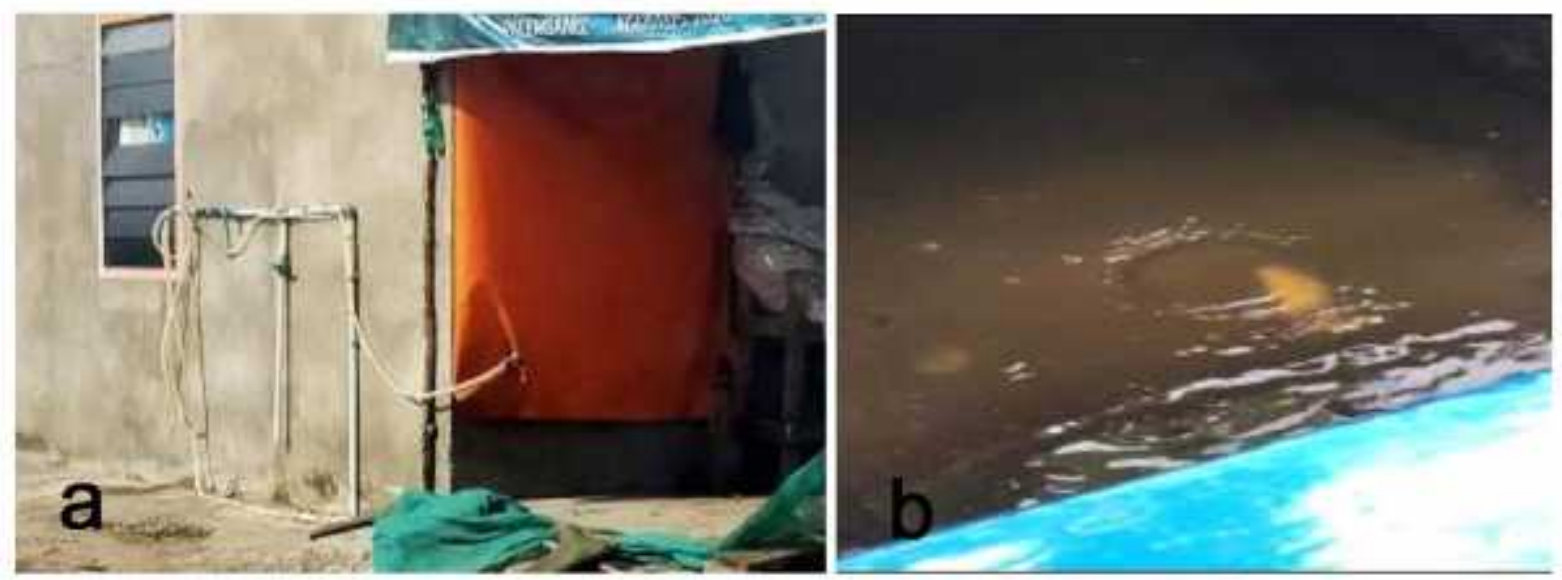

Gambar 6. (a). Plastik penampung biogas, (b). Pupuk organik pada outlet

\section{KESIMPULAN}

Perbaikan pada instalasi biogas ini menghasilkan produk akhir yang optimal yaitu biogas dan pupuk organik dengan penggunaan alat penyaring pada bak inlet yang digunakan untuk memisahkan kotoran sapi dan sisa pakan ternak. Perlakuan pengolahan (treatment) dengan pemisahan bahan baku kotoran sapi dengan rumput pakan dengan menggunakan alat penyaring untuk menghasilkan bahan baku yang baik pada proses fermentasi biogas. Sehingga kotoran sapi yang masuk ke dalam digester dapat difermentasi secara maksimal.

Hasil pengolahan kotoran sapi menjadi pupuk cair dan padat organik serta biogas jika menghasilkan kapasitas yang cukup banyak, tentunya akan berdampak baik bagi masyarakat. Penggunaan pupuk organik tentunya akan memberikan keuntungan bagi para petani sehingga dapat mengurangi penggunaan pupuk kimia. Hasil dari biogas dapat dimanfaatkan bagi rumah tangga untuk memenuhi kebutuhan memasak sehari - hari. Dari pupuk cair dan padat yang dihasilkan, masyarakat dapat meningkatkan nilai ekonomis produk tersebut dengan mengolah dan mengemas produk tersebut agar dapat dijual. Untuk pupuk cair, dapat dilakukan treatment penurunan kadar keasaman ( $\mathrm{pH}$ ) dan penambahan kandungan nutrisi. Untuk pupuk padat, dapat diolah dengan mengambil bagian padatan dari bak outlet.

\section{DAFTAR PUSTAKA}

Mujianto, H., \& Rahmi, M. (2019). Pengaruh Sudut Kemiringan ( INKLINASI ) terhadap Unjuk Kerja Ayakan Getar ( Vibrating Screen ). Jurnal Sigma Teknika, 2(2), 137-142.

Pratiwi, I., Permatasari, R., \& Homza, O. F. (2019a). Pemanfaatan Limbah Kotoran Ternak Sapi dengan Reaktor Biogas di Kabupaten Ogan Ilir. Ikraith-Abdimas, 2(3), 1-10.

Pratiwi, I., Permatasari, R., \& Homza, O. F. (2019b). Produksi biogas dari limbah kotoran sapi dengan digester fixed drum. Jurnal Aptekmas, 2(3), 7-16.

Sulistiyanto, Y., Sustiyah, Zubaidah, S., \& Satata, B. (2016). Pemanfaatan Kotoran Sapi Sebagai Sumber Biogas. Jurnal Udayana Mengabdi, 15(2), 150-158.

Wahyuni, S. (2017). Biogas Hemat Energi Pengganti Listrik, BBM dan Gas Rumah Tangga. Jakarta: PT. Agromedia Pustaka. 